University for Business and Technology in Kosovo

UBT Knowledge Center

UBT International Conference

2017 UBT International Conference

Oct 29th, 5:00 PM - 5:15 PM

\title{
Using of proper pavement material for the Intersections with slow-moving traffic
}

\author{
Bekim Selimi \\ University for Business and Technology, bekim.selimi@ubt-uni.net
}

Follow this and additional works at: https://knowledgecenter.ubt-uni.net/conference

Part of the Civil Engineering Commons

\section{Recommended Citation}

Selimi, Bekim, "Using of proper pavement material for the Intersections with slow-moving traffic" (2017). UBT International Conference. 51.

https://knowledgecenter.ubt-uni.net/conference/2017/all-events/51

This Event is brought to you for free and open access by the Publication and Journals at UBT Knowledge Center. It has been accepted for inclusion in UBT International Conference by an authorized administrator of UBT Knowledge Center. For more information, please contact knowledge.center@ubt-uni.net. 


\title{
USING OF PROPER PAVEMENT MATERIAL FOR THE INTERSECTIONS WITH SLOW-MOVINGTRAFFIC
}

\author{
Bekim Selimi \\ UBT - Higher Education Institution, Prishtinë, Kosovë \\ bekim.selimi@ubt-uni.net
}

\begin{abstract}
Use of proper pavement material for some of intersections need special attention by road designers. At Camp Bondsteel-Kosovo on 2002 were built four road intersections using the concrete as pavement material. Heavy and slow-moving trucks that are turning or accelerating exposed these intersections to some of the highest stress level. After some years this intresections start deteriorating on their surface due to friction. The concrete pavements did not survive this period of usage and after eight years were removed and replaced with asphalt pavements. After more than seven years, the asphalt has shown minor distress but is still in good condition after years of outstanding service. This issue was resolved using aggregate and aggregate blend who meet higher standards. This blend of aggregate has high internal friction developing the degree of interlock needed to resist friction and or shearing. In this case, tough, durable aggregates were necessary, while rounded aggregate avoided in both the coarse and fine fractions. Due to slow-moving traffic on the hot weather, the binder has been selected with higher temperature grade than climate conditions. The asphalt section is still going strong after seven years.
\end{abstract}

Keywords: Intersection, Asphalt, Concrete, Aggregate, Binder.

\section{INTRODUCTION}

Concrete is the most widely used construction material in the world and its presence is felt in numerous ways in our daily lives: the buildings where we live and work and the infrastructure that connects us. Thus, it is no exaggeration to say that concrete lays the foundation for our modern society. In addition, the enormous application of concrete holds the promise that it can be part of the solution, if aided with breakthroughs in concrete science and engineering, to a sustainable development in society and economy while minimizing the ecological footprint. However, popularity does not guarantee immunity. Most of the concrete structures are exposed to the environment where deleterious species can penetrate into concrete via a variety of transport mechanisms, leading to a range of durability related problems and undermining its serviceability, among which, frost damage is one of the most severe and also extensively studied topics.

Pavement designers and contractors have learned that some intersections need special attention. Heavy, slow-moving vehicles that are stopping, turning, or accelerating expose intersections to some of the highest stress levels found on pavements. High-stress locations also include climbing lanes, truck weigh stations, rest areas, and other slow-speed areas. Giving special attention to these areas can ensure that high-stress areas deliver the same outstanding performance as other asphalt pavements.

Pavement engineers have adopted a four-point strategy to ensure good performance for intersections and other high-stress applications.

A basic intersection strategy consists of four steps: 
- Assess the situation.

- Ensure structural adequacy.

- Select high-performance materials and confirm the mixture design.

- Use proper construction techniques.

The key to achieving this desired performance at high-stress installations is recognizing that these pavements may need to be treated differently from regular, posted-speed pavements.

\section{THE DAMAGE PHENOMENA}

\section{PROBLEM STATEMENT}

\section{Freeze-thaw deterioration}

When water freezes, it expands about 9\%. As the water in moist concrete freezes, it produces pressure in the capillaries and pores of the concrete. If the pressure exceeds the tensile strength of the concrete, the cavity will dilate and rupture. The accumulative effect of successive freezethaw cycles and disruption of paste and aggregate can eventually cause significant expansion and cracking, scaling, and crumbling of the concrete. Local weather records can also be referenced to more precisely determine the severity of exposure.

\section{Deicer Scaling}

Damage related to deicing practices is no longer a matter of speculation; distress related to deicer use has occurred in all cold weather states. This has spawned a renewed interest in understanding the effects that deicing and anti-icing practices can have on concrete pavements. Snow and ice removal is critical for the safe operation of the road transportation infrastructure.

Deicing chemicals used for snow and ice removal, such as sodium chloride, can aggravate freeze-thaw deterioration. The additional problem caused by deicers is believed to be a buildup of osmotic and hydraulic pressures in excess of the normal hydraulic pressures produced when water in concrete freezes. In addition, because salt absorbs moisture, it keeps the concrete more saturated, increasing the potential for freeze-thaw deterioration.

\section{Aggregate Expansion}

Some aggregates may absorb so much water (to critical saturation) that they cannot accommodate the expansion and hydraulic pressure that occurs during the freezing of water. The result is expansion of the aggregate and possible disintegration of the concrete if enough of the offending particles are present. If a problem particle is near the surface of the concrete, it can cause a popout (Fig 2). 


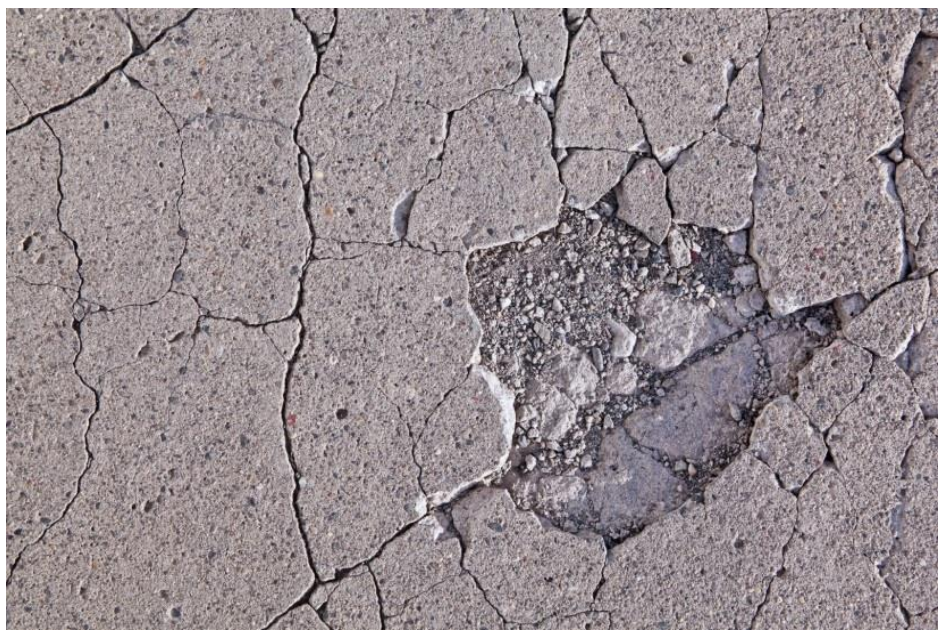

Fig 1: Deteriorated concrete surface due to aggregate expansion

Due to freezing and thawing cycles, cracking of the concrete starts in the saturated aggregate at the bottom of the slab and progresses upward until it reaches the wearing surface.

\begin{abstract}
Abrasion/erosion
Abrasion damage occurs when the surface of concrete is unable to resist wear caused by rubbing and friction. As the outer paste of concrete wears, the fine and coarse aggregate are exposed and abrasion and impact will cause additional degradation that is related to aggregateto-paste bond strength and hardness of the aggregate.

Although wind-borne particles can cause abrasion of concrete, the two most damaging forms of abrasion occur on vehicular traffic surfaces and in hydraulic structures, such as dams, spillways, and tunnels.
\end{abstract}

\title{
Traffic Surfaces
}

Abrasion of floors and pavements may result from production operations or vehicular traffic. Many pavement are subjected to abrasion by steel or hard rubber wheeled traffic, which can cause significant rutting.

Tire chains and studded snow tires cause considerable wear to concrete surfaces. In the case of tire chains, wear is caused by flailing and scuffing as the rotating tire brings the metal in contact with the concrete surface. In some areas, abrasive materials such as sand are applied to pavements to improve traction, but experience has shown that this causes little wear if the concrete is of good quality and the aggregates are wear resistant. 


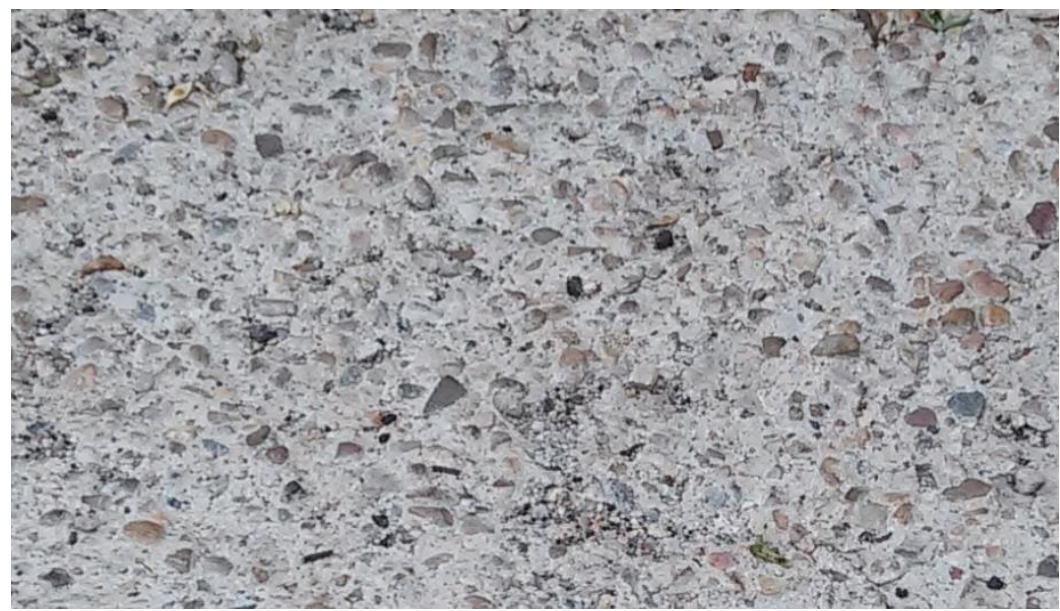

Fig 2: Deteriorated concrete surface at intersections

\section{Physical effects}

Salts in solution will penetrate the porous microstructure of concrete. Subsequent evaporation may result in salt crystal growth within the concrete, which can result in expansive forces. This is not necessarily a cold weather phenomenon; it can also occur in marine or industrial settings. The mechanism most likely to cause distress in a freezing environment is that of expansion of water or solution as it freezes within the paste's pore structure.

Cracking leads to more water on the next thawing cycle, meaning cycling through the freezing point can lead to extensive damage accumulation. The damage occurs when the system is saturated above the point where there is sufficient space for the expanding water to move into.

\section{ADVANCED PAVEMENT MATERIALS}

In order to have better pavement, an initiative was undertaken to improve materials selection and mixture design by developing:

- A new mix design method that accounts for traffic loading and environmental conditions.

- A new method of asphalt binder evaluation.

- New methods of mixture analysis.

\section{PAVEMENT PROCEDURE AND CONSTRUCTION TECHNIQUES}

The pavement mix design method consists of 7 (seven) basic steps:

- Aggregate selection, 
- Asphalt binder selection,

- Sample preparation (including compaction),

- Performance Tests,

- Density and voids calculations,

- Optimum asphalt binder content selection,

- Moisture susceptibility evaluation.

Use of proper construction techniques is of course important for all pavements, and it is critical for high-performance intersections. Three aspects are worth special mention here: proper compaction, avoidance of segregation, and excellent joint construction.

Proper density is vital for long-term durability. The mixture must be properly compacted to resist additional compaction under heavy traffic.

Using this four-step strategy, high-performance intersections have been routinely constructed for years.

After the intersections were rebuilt using this four-step strategy, all four intersections on Camp Bondsteel have provided superior performance without additional maintenance or rehabilitation expenditures in the intervening years.

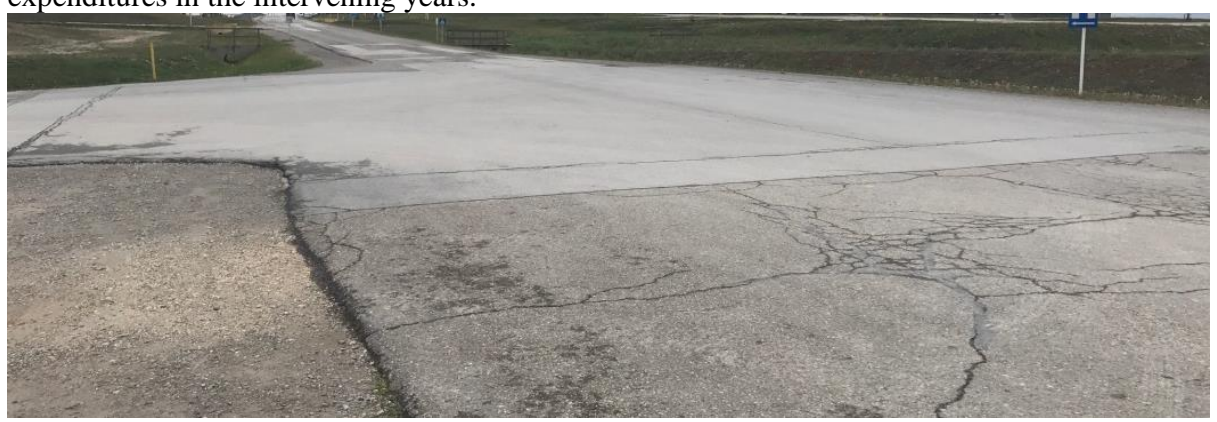

Fig 3: Replaced concrete with asphalt pavement at 1st road intersection on Bondsteel

\section{Aggregate selection}

As the expected traffic loading on the pavement increases, the aggregate and aggregate blend must meet higher standards. A successful blend of aggregate must have high internal friction to develop the degree of interlock needed to resist shearing or rutting. Tough, durable aggregates are necessary. Rounded aggregate must be avoided in both the coarse and fine fractions. The most important properties of aggregates used for pavement construction are: particle size and graduation, hardness or resistance to wear, durability or resistance to weathering, specific gravity and absorption, chemical stability, particle shape and surface tecture, freedom from deletrious particles or substances.

For intersection mixtures, it is particularly important to use a mix design that produces stone-tostone interlock and orientation - without having the stone fracture. 


\section{Asphalt Binder}

There is a binder selection process, which is, of course, tied to the Superpave asphalt binder performance grading (PG) system and its associated specifications. The PG asphalt binders are selected based on the expected pavement temperature extremes in the area of their intended use. The pavement software is using to calculate these extremes and select the appropriate PG asphalt binder using one of the following three alternate methods:

- Pavement temperature. The designer inputs the design pavement temperatures directly.

- Air temperature. The designer inputs the local air temperatures, then the software converts them to pavement temperatures.

- Geographic area. The designer simply inputs the project location. From this, the software retrieves climate conditions from a weather database and then converts air temperatures into pavement temperatures.

Once the design pavement temperatures are determined they can be matched to an appropriate PG asphalt binder.

\section{Design Pavement Temperature}

The mix design method determines both a high and a low design pavement temperature. These temperatures are determined as follows:

- High pavement temperature - based on the 7-day average high air temperature of the surrounding area.

- Low pavement temperature - based on the 1-day low air temperature of the surrounding area.

Based on this can determine the appropriate PG asphalt binder. PG asphalt binders are specified in $6^{\circ} \mathrm{C}$ increments.

\section{Performance Grade Nomenclature}

Pavement performance grading is reported using two numbers - the first being the average seven-day maximum pavement temperature $\left({ }^{\circ} \mathrm{C}\right)$ and the second being the minimum pavement design temperature likely to be experienced $\left({ }^{\circ} \mathrm{C}\right)$. Thus, a PG $58-22$ is intended for use where the average seven-day maximum pavement temperature is $58^{\circ} \mathrm{C}$ and the expected minimum pavement temperature is $-22^{\circ} \mathrm{C}$. These numbers are pavement temperatures and not air temperatures (these pavement temperatures are estimated from air temperatures using an algorithm contained in the program).

For slow-moving traffic, the binder should be selected one high temperature grade higher than climate conditions on the project called for, such as a PG-70 instead of PG-64. 


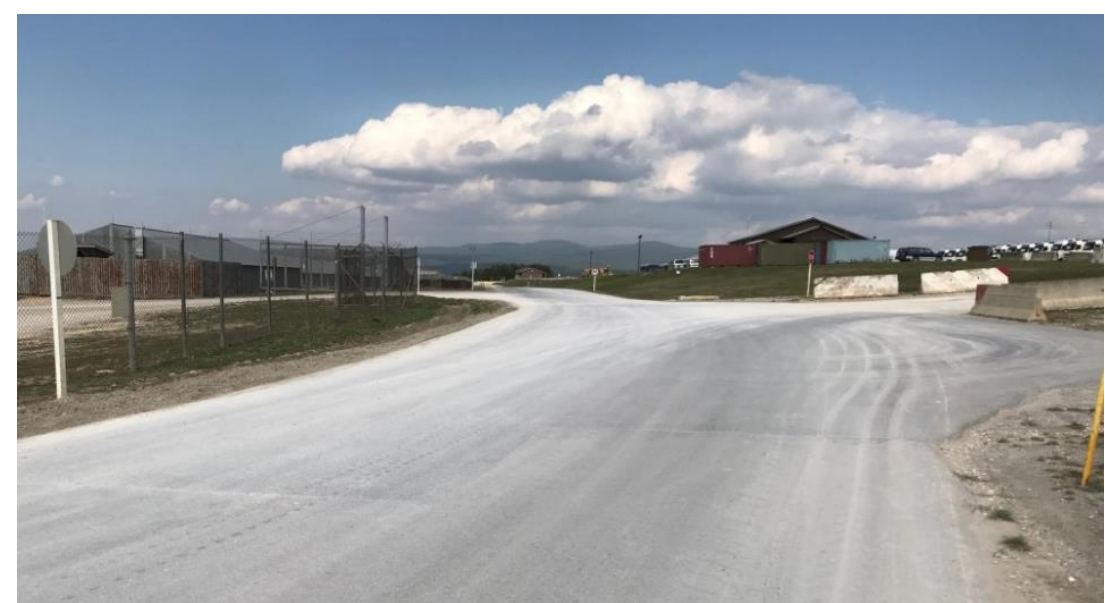

Fig 4: Replaced concrete with asphalt pavement at 2nd road intersection on Bondsteel

\section{CONCLUSIONS}

Safety is the primary consideration, and activities to keep roads safe will not be compromised. Therefore, it is imperative that the concrete pavement industry produces pavements that are able to resist the aggressive environment that will be imposed with increasing use of brinebased deicing systems using chloride salts.

On the other hand, agencies also need to use the range of products available to them wisely.

Consideration may also be given to flushing pavements to remove the salts periodically, but this may not always be practical. It is important to prevent water and salt solutions from being trapped in the joint. This can be improved by ensuring that drainage details are adequate and by avoiding leaving a void below the backer rod.

New concrete pavements should be designed to resist the aggressive environments imposed by deicing salts.

The concrete pavement required frequent lane closures for repairs to address the extensive cracking and deterioration.

Not only is asphalt a more durable pavement than concrete, but it is also the less expensive material to install and repair while providing a safer, smoother surface on which to drive. Asphalt pavements cost less to build and maintain, is 100 percent recyclable, take far less time to construct, no need for 24-hour lane closures, intersections can be opened to traffic as soon as the rollers have finished and the pavement has cooled. In other words, asphalt is miles ahead of the competition.

\section{REFERENCES}

1. W. Paul, 'Highway Engineering' 6th edition; John Wiley \& Sons, INC; 1996.

2. ASPHALT \& ASPHALT PAVING DESIGN GUIDE; Minnesota Asphalt Pavement Association. 
3. Deicing Salts and Concrete Pavements; MAP Brief August 2014. HMA Pavement Mix Type Selection Guide; National Asphalt Pavement Association and Federal Highways Administration, 2001.

4. High-Performance Intersections; Asphalt Pavement Alliance, 2010.

5. Portland Cement Association (PCA), 2002. 